\title{
Improved method for determination of waxes in olive oils: reduction of silica and use of a less hazardous solvent
}

\author{
Andrea Milani ${ }^{1, *}$, Paolo Lucci ${ }^{1}$, Martina Sedran ${ }^{\mathrm{a}}$, Erica Moret $^{1}$, Sabrina Moret ${ }^{1}$ and Lanfranco Conte ${ }^{\mathrm{b}}$ \\ ${ }^{1}$ Dept. of Agro-Food, Environmental and Animal Sciences-University of Udine, Via Sondrio, 2/a, 33100 Udine, Italy
}

Received 2 February 2020 - Accepted 16 March 2020

\begin{abstract}
The evaluation of the content of waxes is request both by IOC Trade Standard and by Regulation (EEC) 2568/91 and its further amendments. The official method uses $15 \mathrm{~g}$ of silicic acid and elutes several fractions by using huge volumes of dangerous solvent (n-hexane). The developed method uses $1 \mathrm{~g}$ of silicic acid with a different particle size and less than $20 \mathrm{~mL}$ of solvent mixture, substituting $\mathrm{n}$-hexane with less toxic isooctane. Briefly, after spiking with a suitable internal standard, oil sample is fractionated by SPE (Solid Phase Extraction) cartridge with $1 \mathrm{~g}$ of silica, waxes are eluted with $14 \mathrm{~mL}$ of isooctane/ethyl ether 99/1 (6 mL discarded and $8 \mathrm{~mL}$ collected), then, after elution sample is reconstitute in $200 \mu \mathrm{L}$ of nheptane and analysed by capillary GC. Data of "In home" validation, (repeatability, accuracy and recovery) and relative chromatograms are reported in this paper.
\end{abstract}

Keywords: olive oils / oil purity / waxes / Solid Phase Extraction / gas chromatography

\begin{abstract}
Résumé - Amélioration de la méthode de détermination des cires dans les huiles d'olive : réduction de la silice et utilisation d'un solvant moins nocif. L'évaluation de la teneur de cires est demandée à la fois par la norme commerciale de l'IOC (International Olive Council) et par le règlement (CEE) n $n^{\circ} 2568 / 91$ et ses modifications ultérieures. La méthode officielle utilise $15 \mathrm{~g}$ d'acide silicique et des volumes importants de solvant dangereux (n-hexane). La méthode développée utilise $1 \mathrm{~g}$ d'acide silicique avec une taille de particules différente et moins de $20 \mathrm{~mL}$ de mélange de solvants, en remplaçant le n-hexane par de l'isooctane moins toxique et moins volatil. Ainsi, après l'introduction d'un étalon interne, l'échantillon d'huile est fractionné par cartouche SPE (Solid Phase Extraction) avec $1 \mathrm{~g}$ de silice, les cires sont extraites avec $14 \mathrm{ml} \mathrm{d}$ 'isooctane/éther éthylique 99/1 ( $6 \mathrm{~mL}$ éliminés et $8 \mathrm{~mL}$ collectés), puis, après extraction, l'échantillon est reconstitué en $200 \mu \mathrm{L}$ de n-heptane et analysé par chromatographie en phase gazeuse capillaire. Les données de la validation (répétabilité, précision et récupération) et les chromatogrammes relatifs sont présentés dans cet article.
\end{abstract}

Mots clés : huiles d'olive / pureté de l'huile / cires / extraction en phase solide / chromatographie en phase gazeuse

\section{Introduction}

The production chain of oils from olive fruits involves a mechanical extraction, that leads to two edible categories named extra virgin (EVOO) and virgin (VOO) and one not suitable for human consumption, named lampante (LOO), while the by product, named "olive pomace" that still contains some amounts of oil is extracted by means of solvent, as happens for most of the seed oils.

EVOO is the most valuable and, hence the one that had been prone to frauds, even if considered in an historical perspective.

A number of methods had been developed and approved as official worldwide (European Commission, 1991) to

\footnotetext{
*Correspondence: andrea.milani.1@spes.uniud.it

${ }^{\text {a }}$ Part of this work as BSc Diploma thesis.

${ }^{\mathrm{b}}$ At present retired.
}

highlight faked oils; this reduced so much the possibility to mix seed oils, thanks to the assessment of fatty acids composition and later of sterols composition; in the past this moved attention of frauders to the use of olive pomace oil to perform frauds by mixing this solvent extracted oil to mechanical extracted ones.

The measurement of the amount of erythrodiol and uvaol, two triterpenic dialcohols mainly present in the fruit skin, was adopted by Italian National law since 1975, after they were studied by Jacini and Fedeli (1972) and the method adopted at national level (NGD method, 1985).

Later, in 1991, the Reg (EEC) 2568/91 (European Commission, 1991) adopted this parameter.

Some technological means were however developed to remove huge amounts of these dialcohols so that Camera (19811983) proposed the so called "alcoholic index" as a suitable tool to discover this illegal practice; later, Tiscornia et al. (1985) 
slightly modified the Camera's method by proposing the "Alkanols" content evaluation.

The rationale for this depends on the presence of high concentration of waxes that, after saponification (a step used to prepare the unsaponifiable fraction for the analysis of sterols), give rise to fatty acids and aliphatic alcohols.

The alkanols method was extensively applied and this highlighted the existence of selected oils (mainly from Greece) that presented concentration of alkanols high enough to exceed the legal limit, even if mechanically extracted.

Later, Mariani et al. (1991) highlighted the presence of high amounts of alcohols but low amounts of waxes, Mariani and Fedeli (1986) proposed the measurement of the content of waxes as a suitable analytical tool to assess the mixture with solvent extracted oils.

The method involves the pre-separation of the waxes fraction by liquid chromatography by using a silica column, followed by GC analysis.

Some drawbacks of the method are the use of a discrete amount of silica $(15 \mathrm{~g})$, the use of relevant volumes of solvent (about $360 \mathrm{~mL}$ ) and last but not least, the use of n-hexane, that is nowadays considered as healthy risk solvent. Of course, the experimental conditions result as time consuming, in fact, Mariani himself proposed within the International Olive Council (IOC) oil chemists working group, the use of $3 \mathrm{~g}$ of silica and the method is present in the IOC as provisional adopted (International Olive Council, 2012).

In the present work, some modifications of the method are proposed, namely the use of a different silica that admit to reduce its amount at $1 \mathrm{~g}$, as a consequence, a lower volume of solvent (less than $20 \mathrm{~mL}$ ) is used; furthermore, isooctane was used instead of n-hexane, that is suspected of damaging fertility and that may cause damage to organs (nervous system) (H361f, H373). In a previous paper, Nota et al. (1999) proposed the use of $1 \mathrm{~g}$ of silica gel, however, the use of high toxic solvent (carbon tetrachloride) was proposed, too.

The establishment of limits underwent to some modifications, depending on poor separation obtained by some laboratories of ester $\mathrm{C} 40$ from phityl Behenate that make its measure subject to erroneous data: for this reason IOC decided not to include $\mathrm{C} 40$ in the calculation of the total waxes content in the case of extra virgin and virgin oil. For these oil, the limit had been established at $\leq 150 \mathrm{mg} / \mathrm{kg}$, while for lampante oil it is $\leq 300 \mathrm{mg} / \mathrm{kg}$ and for pomace (any one) $>350 \mathrm{mg} / \mathrm{kg}$ (International Olive Council, 2018).

A peculiar topic is the possibility of increasing of waxes concentration along oil ageing, as demonstrated by Mariani and Venturini (2006), mainly in oil with high concentration of free fatty acids.

\section{Experimental procedures}

\subsection{Samples}

Three different oils were used: an extra virgin olive oil (EVOO), low acidity $(0.30 \%)$, one year old, Refined Olive Oil (ROO) and Lampante oil (LOO), one year old.

\subsection{Chemicals}

Silicic acid 60: 0.015-0.04 mm (Macherey-Nagel Duren Germany, Cat. No. 815650)
Isooctane, diethyl ether, n-heptane analytical grade.

Wax C32 (internal standard): Lauryl arachidate (Sigma Aldrich Milan, Italy, Cat No. A8671), n-heptane solution $0.02 \mathrm{mg} / \mathrm{mL}$ in the case of virgin and lampante oil or $0.04 \mathrm{mg} /$ $\mathrm{mL}$ in the case of olive pomace oil.

\subsection{Apparatus}

SPE (Solid Phase Extraction) glass tubes $6 \mathrm{~mL}$ with PTFA frits, i.d. $12 \mathrm{~mm}$ (Sigma Aldrich Milan, Italy, Cat No504394)

SPE manifold (Sigma Aldrich, Milan, Italy).

Gas chromatograph equipped with cold on column injector and FID detector (Fison's MEGA 5300 - Fison's Milan Italy).

Fused silica capillary column $8 \mathrm{~m} \times 0.32 \mathrm{~mm}$ i.d. $\times 0.10$ $\mu \mathrm{m}$ stationary phase, coated with MEGA-5 stationary phase (MEGA, Milan, Italy).

Microsyringe for on column injection $10 \mu \mathrm{L}$, with hardened needle.

Rotary evaporator (Büchi, Switzerland).

Ordinary laboratory glassware.

Analytical balance for weighting to an accuracy of within $\pm 0.1 \mathrm{mg}$.

\subsection{Procedure}

\subsubsection{Solid phase extraction cartridge preparation}

The glass SPE cartridge was prepared transferring $1 \mathrm{~g}$ of silica into it between two frits, one above and one below the silica layer, then, the cartridge was attached to the vacuum chamber and conditioned with $5 \mathrm{~mL}$ of isooctane and this fraction was discharged.

\subsubsection{Sample preparation and analytical conditions}

$200 \mu \mathrm{l}$ of internal standard solution was put in a screw cap tube, then solvent is evaporated by a gentle nitrogen stream and about $50 \pm 1 \mathrm{mg}$ of oil are added then dissolved in $0.5 \mathrm{~mL}$ of isooctane.

The sample prepared as descripted above, was quantitatively loaded into the SPE cartridge and the solvent was eluted just above the frit on top of the silica, this volume of solvent was discarded.

Waxes are then eluted with $14 \mathrm{~mL}$ isooctane/ethyl ether mixture at $99: 1, \mathrm{v} / \mathrm{v}$ discarding the first $6 \mathrm{~mL}$ and collecting the following $8 \mathrm{~mL}$ in a $10 \mathrm{~mL}$ ground glass stopper tube. During this step, the column was not allowed to run dry. Vacuum was applied to obtain a flow of about 1 drop every second. The resultant fraction was dried in a rotary evaporator under reduced pressure until all the solvent has been eliminated. Then $200 \mu \mathrm{L}$ of $\mathrm{n}$-heptane were added and the solution was analysed by GC-FID applying the following operative conditions: temperature of detector (FID) was set at $350{ }^{\circ} \mathrm{C}$, temperature of the oven programmed from $80^{\circ} \mathrm{C}$ (1 minute isotherm), then increased to $240^{\circ} \mathrm{C}$ at a rate of $20^{\circ} \mathrm{C} / \mathrm{min}$, then to $270{ }^{\circ} \mathrm{C}$ at a rate of $7.5^{\circ} \mathrm{C} / \mathrm{min}$, lastly to $340^{\circ} \mathrm{C}$ at a rate of $10^{\circ} \mathrm{C} / \mathrm{min}$. Final isotherm is maintained for 20 minutes.

Helium was used as carrier gas, at a constant pressure of $30 \mathrm{kPa}$, hydrogen at $50 \mathrm{kPa}$, air at $80 \mathrm{kPa}$.

Figure 1 reports the flow chart of the proposed procedure. 


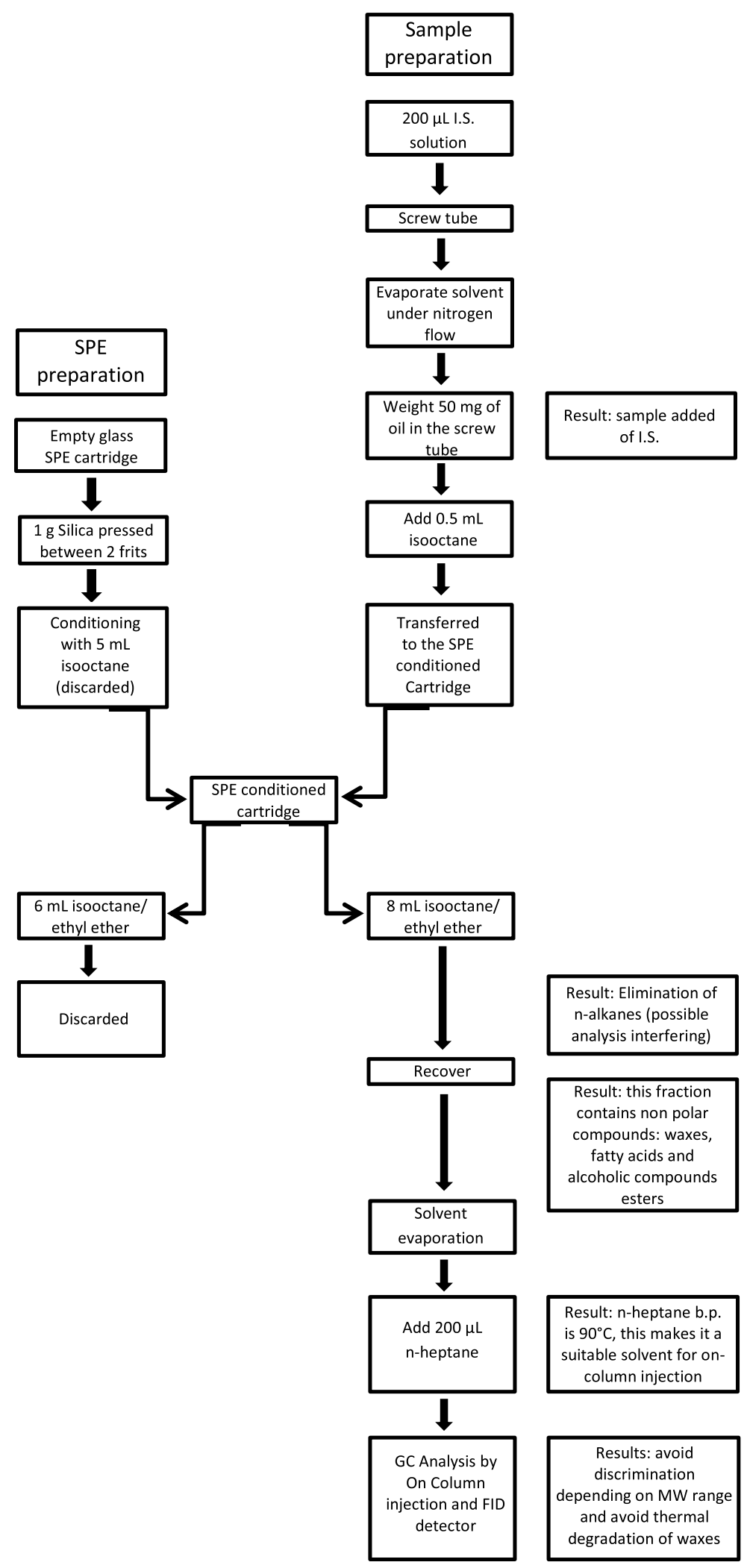

Fig. 1. Flow chart of the proposed method. 
Table 1. Validation of the method by using EVOO.

\begin{tabular}{|c|c|c|c|c|c|c|c|c|c|}
\hline & \multicolumn{7}{|c|}{ Waxes $(\mathrm{mg} / \mathrm{kg})$} & SD & RSD \\
\hline $\mathrm{C} 40$ & 10.77 & 10.22 & 12.89 & 8.96 & 9.72 & 10.40 & 10.45 & 0.62 & 5.97 \\
\hline C44 & 4.24 & 3.97 & 5.08 & 5.56 & 4.13 & 4.30 & 4.55 & 0.63 & 13.82 \\
\hline $\mathrm{C} 46$ & 7.95 & 7.25 & 7.30 & 6.69 & 7.55 & 7.68 & 7.40 & 0.43 & 5.84 \\
\hline
\end{tabular}

\subsection{Calculation}

The amount of waxes is calculated by the following formula:

$$
\mathrm{C}_{\mathrm{x}} \mathrm{Wax}, \mathrm{mg} / \mathrm{kg}=\frac{\mathrm{A}_{\mathrm{x}} * \mathrm{Ms} * 1000}{\mathrm{As} * \mathrm{M}},
$$

Where:

$-A_{x}=$ Area of peak of wax $x$;

- Ms = internal standard mass (mg);

- As $=$ Area of peak of internal standard;

$-\mathrm{M}=$ mass of the sample $(\mathrm{g})$.

Results are reported with two decimal figures and sum of single wax concentration is reported.

\subsection{Method validation}

The method had been validated by calculating repeatability according to the following steps:

- Calculation of mean;

- Calculation of standard deviation;

- Calculation of relative standard deviation.

\section{Results and discussion}

The method had been in house validated by performing six replicated analysis of three different oils.

Mean, standard deviation and relative standard deviation had been calculated and data are reported in the following tables; furthermore, recovery and accuracy were evaluated, by analysing a sample of refined hazelnut oil, spiked with a known amount of synthetic waxes.

Table 1 reports data obtained by analysing an EVOO. The RSD of the proposed method (2.51) is closed to the one reported within the IOC method: bearing in mind that in the case of EVOO only waxes $\mathrm{C} 42, \mathrm{C} 44$ and $\mathrm{C} 46$ must be considered to obtain the sum, the value of this method is $2.51 \%$, while the IOC method (International Olive Council, 2017) reports $\mathrm{RSD} \%=2.7 \%$ when waxes concentration is $125 \mathrm{mg} / \mathrm{kg}$ or $2.29 \%$ when waxes concentration is $26 \mathrm{mg} / \mathrm{kg}$ : that's to say a comparable concentration.

Even if, as already said, the IOC standard does not consider C40 in the case of EVOO, we did because the sum enclosing C40 will be useful when comparing theoretical and experimental data in the case of ROO/EVOO blends (see later in this paper).
In Figure 2 is reported the GC chromatogram of the EVOO oil analysed with relative enlargement of the waxes area.

Data reported in Table 2 deal with validation carried out using refined olive oil. In this case, the content of waxes is higher than extra virgin; the IOC Trade Standard fixed a limit $\leq 350 \mathrm{mg} / \mathrm{kg}$ and the mean of waxes concentration of sample used for the validation in this study is $331.87 \mathrm{mg} / \mathrm{kg}$ that makes it comparable to the sample containing $346 \mathrm{mg} / \mathrm{kg}$ and $479 \mathrm{mg} /$ $\mathrm{kg}$ reported in the validation data of IOC; in this case, too, the RSD obtained in the present study for repeatability (1.90) is comparable to the IOC RSD r $(1.5$ and $1.44 \%)$.

In Figure 3 is shown the Refined olive oil GC chromatogram.

Data of validation in the case of lampante oil are reported in Table 3. This sample respect the limit established for a Lampante oil $(\leq 300 \mathrm{mg} / \mathrm{kg})$; is important to underline the possibility that a lampante oil could cross this limit if aged and characterized by an high free acidity; Mariani and Venturini (2006) highlighted the possibility of a strong increase of waxes concentration in high acidity oils during ageing.

IOC Waxes method that uses $3 \mathrm{~g}$ of silica reports data for oils that can be classified as lampante on the basis of ethyl esters so we could compare our results on the basis of concentration only, the closely one to our data is $310 \mathrm{mg} / \mathrm{kg}$ with a RSD of repeatability of $2.51 \%$, in this case, our results are better.

In Figure 4 is reported the lampante oil chromatogram where there is also highlighted by a brace the presence of methyl- and ethyl esters.

Recovery and accuracy were evaluated by analysing, with 6 replicates, a sample of refined hazelnut oil spiked with a known amount of synthetic waxex C40-C46 (335 mg/kg of total waxes).

The GC trace is reproduced in Figure 5, while results are reported in Table 4.

Recovery can be considered as quantitative as its mean is $99.51 \% \pm 0.85$.

To obtain a further validation of this method two different solutions of ROO spiked with $5 \%$ and $10 \%$ of EVOO were prepared and the analyses of both of them were performed in triplicate. The means of obtained results are very close to theoretical recovery that are $316.95 \mathrm{mg} / \mathrm{Kg}$ for the $5 \%$ solution and $302.04 \mathrm{mg} / \mathrm{Kg}$ for the $10 \%$ solution of EVOO in ROO respectively, as shown in Tables 5 and 6 . The theoretical recovery is calculated based on the mean concentration obtained for the six replicates of pure EVOO and ROO with the following equations: 
Table 2. Validation of the method by using Refined olive oil.

\begin{tabular}{|c|c|c|c|c|c|c|c|c|c|}
\hline & \multicolumn{7}{|c|}{ Waxes $(\mathrm{mg} / \mathrm{kg})$} & SD & RSD \\
\hline $\mathrm{C} 40$ & 91.65 & 94.50 & 88.62 & 100.78 & 94.53 & 100.54 & 95.10 & 4.82 & 5.07 \\
\hline $\mathrm{C} 42$ & 102.23 & 104.17 & 105.22 & 100.25 & 97.90 & 100.54 & 101.72 & 2.71 & 2.66 \\
\hline $\mathrm{C} 44$ & 85.51 & 88.37 & 87.61 & 90.66 & 89.34 & 93.10 & 89.10 & 2.61 & 2.93 \\
\hline $\mathrm{C} 46$ & 46.84 & 47.10 & 44.74 & 46.05 & 45.00 & 45.96 & 45.95 & 0.95 & 2.06 \\
\hline
\end{tabular}

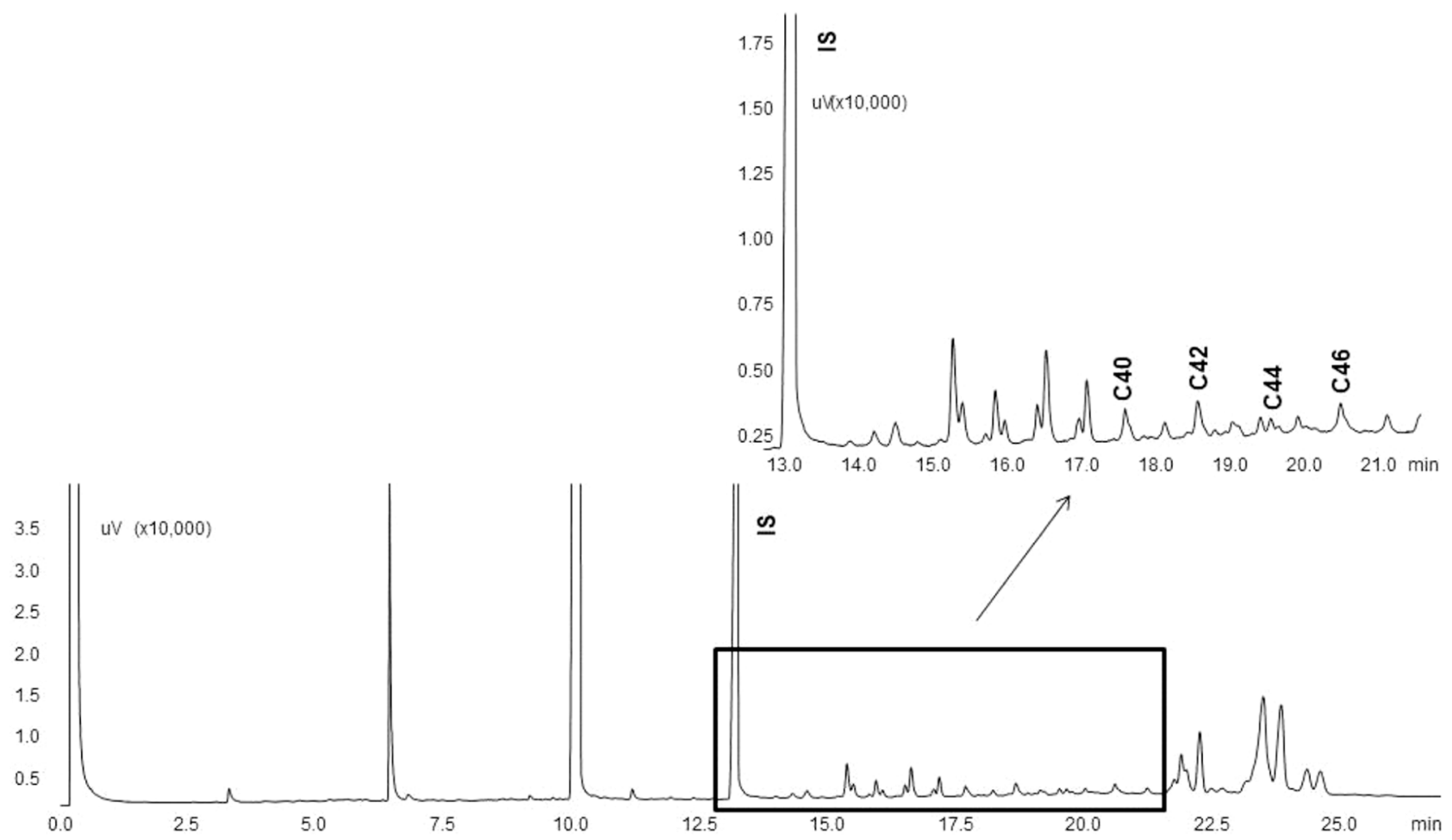

Fig. 2. Gas chromatogram of Extra Virgin Olive Oil. Peaks of waxes are identified on the basis of their carbon number, IS = internal standard, lauryl arachidate.

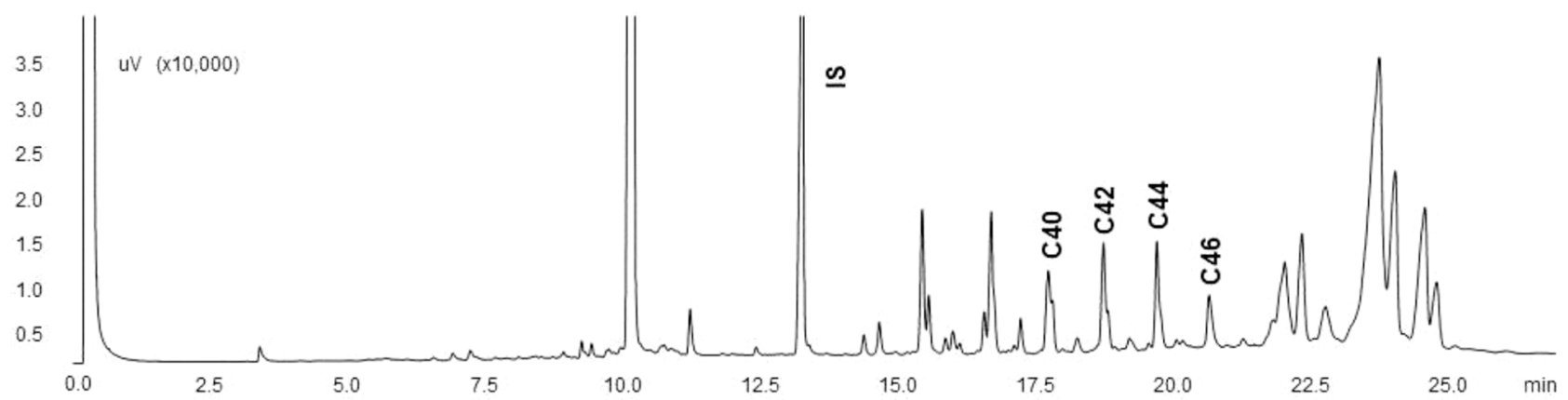

Fig. 3. Gas chromatogram of refined olive oil. Peaks of waxes are identified on the basis of their carbon number, IS $=$ internal standard, lauryl arachidate. 
Table 3. Validation of the method by using a Lampante oil.

\begin{tabular}{|c|c|c|c|c|c|c|c|c|c|}
\hline & \multicolumn{7}{|c|}{ Waxes $(\mathrm{mg} / \mathrm{kg})$} & SD & RSD \\
\hline $\mathrm{C} 40$ & 89.96 & 94.80 & 89.52 & 92.46 & 89.44 & 95.25 & 91.91 & 2.66 & 2.89 \\
\hline $\mathrm{C} 44$ & 66.64 & 67.19 & 64.77 & 66.37 & 63.89 & 66.62 & 65.91 & 1.28 & 1.95 \\
\hline $\mathrm{C} 46$ & 32.27 & 31.71 & 29.81 & 30.57 & 30.54 & 32.35 & 31.21 & 1.05 & 3.36 \\
\hline
\end{tabular}

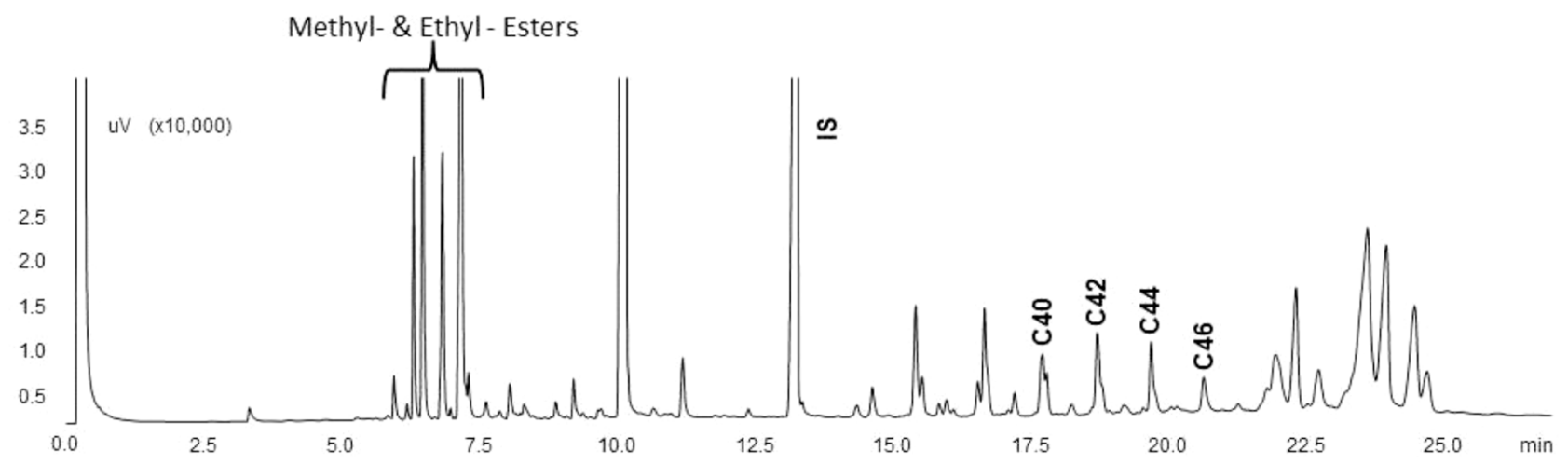

Fig. 4. Gas chromatogram of "Lampante" olive oil. Peaks of waxes are identified on the basis of their carbon number, IS=internal standard, lauryl arachidate, Between 5 and 10 minutes, methyl and ethyl esters of palmitic and oleic acids are eluted.

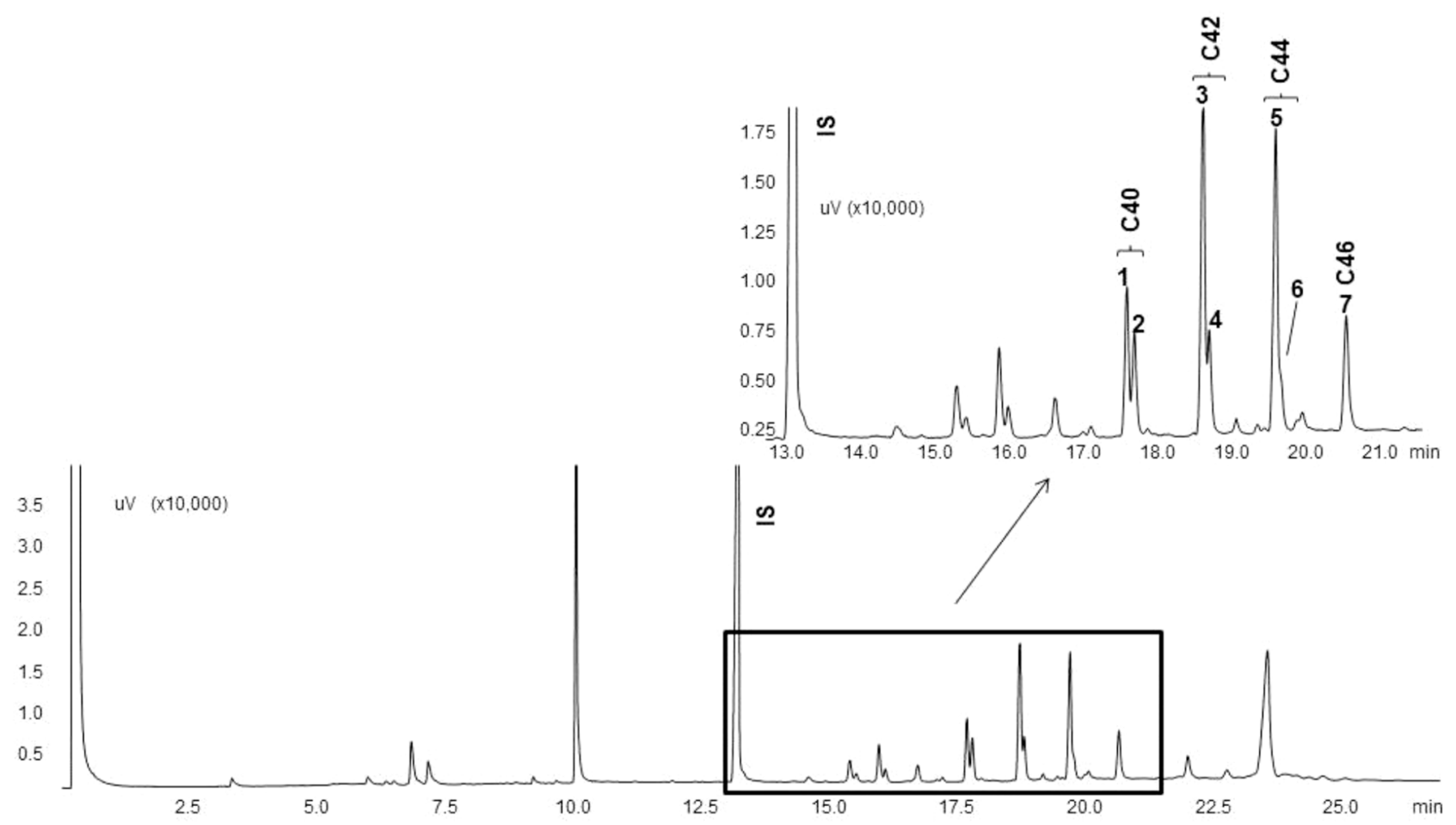

Fig. 5. Gas chromatogram of refined hazelnut oil spiked with a known amount of synthetic waxes C40-C46. Peak identification: 1 : $\mathrm{C}_{22}-$ $\mathrm{OH}+\mathrm{C}_{18: 1}-\mathrm{COOH} ; 2: \mathrm{C}_{24}-\mathrm{OH}+\mathrm{C}_{16: 0}-\mathrm{COOH} ; 3: \mathrm{C}_{24}-\mathrm{OH}+\mathrm{C}_{18: 1}-\mathrm{COOH} ; 4: \mathrm{C}_{26}-\mathrm{OH}+\mathrm{C}_{16: 0}-\mathrm{COOH} ; 5: \mathrm{C}_{26}-\mathrm{OH}+\mathrm{C}_{18: 1}-\mathrm{COOH} ; 6: \mathrm{C}_{28}-$ $\mathrm{OH}+\mathrm{C}_{16: 0}-\mathrm{COOH} ; 7: \mathrm{C}_{28}-\mathrm{OH}+\mathrm{C}_{18: 1}-\mathrm{COOH} ; \mathrm{IS}=$ internal standard, lauryl arachidate. 
Table 4. Results of waxes recovery in spiked sample.

\begin{tabular}{|c|c|c|c|c|c|c|c|c|c|}
\hline & \multicolumn{7}{|c|}{ Waxes $(\mathrm{mg} / \mathrm{kg})$} & SD & RSD \\
\hline $\mathrm{C} 40$ & 70.56 & 71.70 & 70.49 & 70.72 & 71.52 & 70.09 & 70.85 & 0.63 & 0.89 \\
\hline $\mathrm{C} 42$ & 123.61 & 123.33 & 121.56 & 123.16 & 123.61 & 122.65 & 122.99 & 0.79 & 0.64 \\
\hline $\mathrm{C} 44$ & 100.21 & 101.55 & 98.64 & 101.60 & 100.88 & 99.54 & 100.40 & 1.17 & 1.17 \\
\hline $\mathrm{C} 46$ & 38.78 & 39.28 & 37.81 & 39.68 & 39.58 & 39.59 & 39.12 & 0.72 & 1.85 \\
\hline
\end{tabular}

Table 5. Waxes concentration for the 5\% EVOO/95\% ROO solution.

\begin{tabular}{|c|c|c|c|c|c|c|}
\hline & \multicolumn{3}{|c|}{ Waxes $(\mathrm{mg} / \mathrm{kg})$} & Mean & SD & RSD \\
\hline $\mathrm{C} 40$ & 96.27 & 97.14 & 96.46 & 96.63 & 0.46 & 0.47 \\
\hline $\mathrm{C} 42$ & 94.31 & 94.26 & 93.97 & 94.18 & 0.19 & 0.20 \\
\hline $\mathrm{C} 44$ & 81.63 & 80.87 & 81.99 & 81.49 & 0.57 & 0.71 \\
\hline $\mathrm{C} 46$ & 43.38 & 43.98 & 44.14 & 43.83 & 0.40 & 0.91 \\
\hline
\end{tabular}

* Recovery is related to the theoretical concentration of the solution obtained by the mixture of ROO and EVOO in the ratio 95:5.

Table 6. Waxes concentration for the $10 \% \mathrm{EVOO} / 90 \%$ ROO solution.

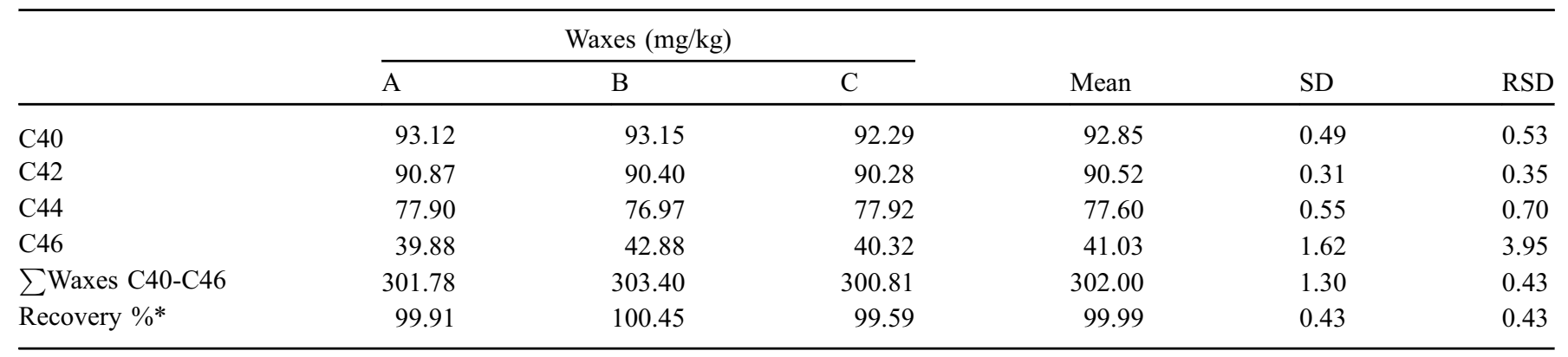

* Recovery is related to the theoretical concentration of the solution obtained by the mixture of ROO and EVOO in the ratio $90: 10$.

$\mathrm{WAX}_{\mathrm{EVOO}} \times 0.05+\mathrm{WAX}_{\mathrm{ROO}} \times 0.95($ for $5 \% \mathrm{EVOO} / 95 \%$ ROO solution);

$\mathrm{WAX}_{\mathrm{EVOO}} \times 0.10+\mathrm{WAX}_{\mathrm{ROO}} \times 0.90($ for $10 \% \mathrm{EVOO} /$ $90 \%$ ROO solution).

\section{Conclusions}

The method developed seems reliable to be used for waxes evaluation as a possible alternative to the IOC and EU official ones, in terms of recovery and repeatability.

Advantages are the use of lower amounts of silica and solvent (about $20 \mathrm{~mL}$ and $1 \mathrm{~g}$ vs $360 \mathrm{~mL}$ and $15 \mathrm{~g}$ ) and the use of a less dangerous solvent (isooctane instead of n-hexane). Consequently, the time required to perform the analysis for what concerns sample preparation is drastically reduced and the difference can be roughly estimated as $20 \mathrm{~min} v s$ more than 300 min: this aspect meets the more recent trends that are moving to a revision of existing methods with the aim to reduce the use of health dangerous solvents in the laboratory routine. Furthermore the use of glass SPE cartridges, compared to polimeric ones, not only avoids the elution of monomers and oligomers but also reduces the plastic waste in the laboratory.

Conflict of interest. Authors declare no conflict of interest.

\section{Funding}

This research did not received any specific grant from funding agencies in the public, commercial or not-for-profit sectors. 


\section{Abbreviation}

$\begin{array}{ll}\text { EVOO } & \text { Extra Virgin Olive oil } \\ \text { OPO } & \text { Olive Pomace Oil } \\ \text { SPE } & \text { Solid Phase Extraction } \\ \text { OC } & \text { On Colum Injection } \\ \text { GC } & \text { Gas Chromatography } \\ \text { SS } & \text { Sum of Squares of differences of data } \\ & \text { minus mean value } \\ \text { SD } & \text { Standard deviation } \\ \text { SDM } & \text { Standard deviation of mean }\end{array}$

Acknowledgements. Authors thank Dr. Carlo Mariani for kindly giving the sample of hazelnut oil spiked with synthetic waxes.

\section{References}

Camera L. 1981. The determination of addition of husk oil to olive oil by GLC of unsaponifiable alcoholic fraction. Annali dell'Istituto Sperimentale per la Elaiotecnica 9: 78-87.

European Commission Reg. (EEC) 2568/91. 1991. Eur Off J L 28. International Olive Council, IOC/T.20/Doc. No.31/2012. 2012. Method of analysis determination of the content of waxes, fatty acid methyl esters and fatty acid ethyl esters by capillary gas chromatography using $3 \mathrm{~g}$ of silica.
International Olive Council IOC/T.20/Doc. No. 28/Rev. 2/2017. 2017. Method of analysis determination of the content of waxes, fatty acid methyl esters and fatty acid ethyl esters by capillary gas chromatography.

International Olive Council, IOC/T.15/NC No.3/Rev. 12/June 2018. 2018. Trade standard applying to olive oils and olive pomace oils.

Jacini G, Fedeli E. 1972. Acidi triterpenici dell'olio di olive. Rendiconti dellistituto Lombardo di Scienze e Lettere Scienze Biologiche 106: 446-451.

Mariani C, Fedeli E. 1986. Individuazione di oli di estrazione in quelli di pressione. Riv Ital Sostanze Gr 63: 3-10.

Mariani C, Venturini S. 2006. Sull'incremento delle cere negli oli d'oliva durante la conservazione. Riv Ital Sostanze Gr 82: 105-114.

Mariani C, Fedeli E, Grob K, Artho A. 1991. Indagine sulle variazioni dei componenti minori liberi ed esterificati di oli ottenuti da olive in funzione della maturazione e dello stoccaggio. Riv Ital Sostanze Gr 68: 178-187.

Nota G, Naviglio D, Romano R, Sabia V, Spagna Musson S, Improta C. 1999. Determination of the wax ester content in olive oils. Improvement in the method proposed by EEC Regulation 183/93.J Agr Food Chem 47: 202-205. https://doi.org/10.1021/jf980648j.

Stazione Sperimentale per le Industrie degli Oli e dei Grassi-Milano Norme Grassi e derivati Metodo NGD C 52: 1985.

Tiscornia E, Fedeli E, Bocca A. 1985. On the possibility to assess the genuineness of pressure extracted olive oil by means of the determination of its content of Alkanols. Note 1: Concentration of alkanols in edible virgin olive oils, lampante olive oils, solvent extracted from olive husk oils. Riv Ital Sostanze Gr 62: 287-293.

Cite this article as: Milani A, Lucci P, Sedran M, Moret E, Moret S, Conte L. 2020. Improved method for determination of waxes in olive oils: reduction of silica and use of a less hazardous solvent. OCL 27: 20. 